\title{
Synergistic protective effect of FTY720 and vitamin E against simulated cerebral ischemia in vitro
}

\author{
XIN PANG and XUENING HOU

\begin{abstract}
Key Laboratory for Corneal Tissue Engineering, College of Marine Life Sciences,
\end{abstract} \\ Ocean University of China, Qingdao, Shandong 266003, P.R. China
}

Received December 24, 2015; Accepted February 14, 2017

DOI: $10.3892 / \mathrm{mmr} .2017 .6572$

\begin{abstract}
The purpose of the present study was to explore the combination effect of FTY720 and vitamin E on cerebral ischemia. Astrocytes were isolated from newborn Sprague-Dawley rats and were subjected to FTY720, vitamin E, or combination of the two. The astrocyte cultures were then exposed to oxygen-glucose deprivation (OGD) to simulate an ischemic model in vitro. Cell viability, lactate dehydrogenase (LDH) leakage and cell apoptosis were detected following $12 \mathrm{~h}$ of exposure to OGD. In addition, the levels of tumor necrosis factor (TNF)- $\alpha$, interleukin (IL)-6, IL-1 $\beta$, total antioxidant capacity, intercellular adhesion molecule (ICAM)-1, vascular cell adhesion molecule (VCAM)-1, chemokine (C-X-C motif) ligand (CXCL)-10, heme oxygenase (HO)-1 and superoxide dismutase (SOD)-1 were measured. Pre-treatment with FTY720 or vitamin E significantly elevated the cell viability and decreased LDH release and number of apoptotic cells. Combination treatment with FTY720 and vitamin $\mathrm{E}$ demonstrated a synergistic protective effect on OGD-induced cell viability, toxicity and apoptosis. Pre-treatment with FTY720 markedly reduced the release of IL-1 $\beta$, TNF- $\alpha$, IL-6, ICAM-1, VCAM-1 and CXCL-10, and pre-treatment with vitamin $\mathrm{E}$ increased the levels of antioxidant, HO-1 and SOD-1. However, pre-treatment with FTY720 combined with vitamin E revealed a synergistic effect. Pre-treatment with FTY720 combined with vitamin E exerts synergistic neuroprotective effects in the simulated cerebral ischemia in vitro.
\end{abstract}

\section{Introduction}

Stroke is a heterogeneous disease with high prevalence worldwide. It has been estimated that $>200$ million patients suffer from stroke annually leading to $\sim 150$ million deaths

Correspondence to: Dr Xin Pang, Key Laboratory for Corneal Tissue Engineering, College of Marine Life Sciences, Ocean University of China, 5 Yushan Road, Shinan, Qingdao, Shandong 266003, P.R. China

E-mail: pangxin0533@126.com

Key words: cerebral ischemia, FTY720, vitamin E, synergistic protective effect per year (1). Cerebral ischemia accounts for more than $80 \%$ of all stroke patients and it is a major cause of morbidity and mortality and is the third cause of disability worldwide (2-4). It is characterized by a severe reduction in cerebral blood flow accompanying with cerebral edema, formation of free radicals and a rapid and substantial local inflammatory reaction (5). Although thrombolytic therapy is now well-established treatment for ischemic stroke, few patients are able to benefit from thrombolytic therapy due to the limited time window (6). Therefore, it is essential to develop effective therapeutic strategies to ameliorate neural damage.

FTY720 and vitamin E have gained interest in the treatment of cerebral ischemia due to their unique pharmacological effects. FTY720, an agonist of sphingosine-1-phosphate (S1P) receptor-1 (S1P1), -3, -4 and -5 (7), exerts immunomodulatory actions by inhibiting the production, egress, trafficking and apoptosis of lymphocytes (8-10). In addition to the immunosuppressive activities, FTY720 has been reported to have the ability of enhancing the integrity of the blood brain barrier (11) and to alleviate infarctions and promote cell regeneration in the central nervous system (CNS) (12). Researchers have recently suggested that FTY720 possesses a neuroprotective effect via S1P1 in ischemic stroke $(13,14)$. In addition, early research has demonstrated that administration of vitamin $\mathrm{E}$ serves a protective role in cerebral ischemia due to its both antioxidant activity and non-antioxidant effects (15). However, little information is available concerning the effects of combination of FTY720 and vitamin E on cerebral ischemia.

Therefore, the present study investigated the combined effects of FTY720 and vitamin E on simulated cerebral ischemia, in addition to the underlying mechanisms. This involved pretreating astrocytes with or without FTY720, vitamin E or combination of both. Following exposure to oxygen-glucose deprivation (OGD) to simulate an ischemic model, pre-treatment with FTY720 and vitamin $\mathrm{E}$ was found to exert synergistic neuroprotective effects in the simulated cerebral ischemia in vitro.

\section{Materials and methods}

Primary culture of astrocytes. Astrocytes were isolated from newborn Sprague-Dawley rat pups (1-day-old; weigh 5-6 g; $\mathrm{n}=10$ ) that were purchased from the Shanghai Laboratory Animal Center (Shanghai, China). The rats were kept under normal animal-house illumination with a $12 \mathrm{~h}$ light/dark 
cycle and access to food and water. The animal experiments were performed according to the National Institutes of Health Guide for Care and Use of Laboratory Animals (Bethesda, MA, USA). Briefly, the cortex of newborn rats was isolated, and the meninges were removed under sterile conditions. The tissues were dissociated mechanically in Dulbecco's modified Eagle medium (DMEM; Sigma-Aldrich; Merck Millipore, Darmstadt, Germany), homogenized and incubated in $0.125 \%$ trypsin at $37^{\circ} \mathrm{C}$ for $20 \mathrm{~min}$. The DMEM medium supplemented with $10 \%$ fetal bovine serum (FBS; Gibco; Thermo Fisher Scientific, Inc., Waltham, MA, USA) was added to stop trypsinization. The suspension was then filtered, centrifuged at $300 \times \mathrm{g}$ for $10 \mathrm{~min}$ at $4^{\circ} \mathrm{C}$ and re-suspended in neurobasal medium (Invitrogen; Thermo Fisher Scientific, Inc.) containing $10 \% \mathrm{FBS}, \mathrm{B}-27,1.0 \mathrm{mM}$ glutamine, $100 \mathrm{U} / \mathrm{ml}$ penicillin and $100 \mathrm{mg} / \mathrm{ml}$ streptomycin (all Sigma-Aldrich; Merck Millipore). The cells $\left(1 \times 10^{6}\right.$ cells $\left./ \mathrm{ml}\right)$ were added to $25 \mathrm{~cm}^{2}$ flasks, incubated in DMEM/F-12 containing $10 \%$ FBS at $37^{\circ} \mathrm{C}$ in a $5 \% \mathrm{CO}_{2}$ incubator. The culture medium was changed every third day. A total of two weeks later, contaminated microglia and oligodendrocytes were removed by shaking for $5 \mathrm{~h}$, and shaking was repeated again after 5 days to remove microglial cells that were detached from the layer of astrocytes. Following successful removal of microglia, astrocytes were collected using $0.125 \%$ trypsin. The purity of astrocytes was $\sim 95-98 \%$, which was identified by analyzing immunofluorescence using anti-glial fibrillary acidic protein (astrocyte marker; Sigma-Aldrich; Merck Millipore). Further analyses were performed on 22-day-old cultures.

Treatment of astrocytes. Astrocytes were randomly assigned to one of five groups: Control group (no medium exposure), medium group (serum-free DMEM exposure), FTY720 group (exposed to serum-free DMEM supplemented with $0.6 \mu$ M FTY720; Novartis, Basel, Switzerland), vitamin E group (exposed to serum-free DMEM supplemented with vitamin E (10 $\mu \mathrm{g} / \mathrm{ml}$, Sigma-Aldrich; Merck Millipore), and FTY720 + vitamin E group (exposed to serum-free DMEM supplemented with FTY720 and vitamin E). Following culture for $24 \mathrm{~h}$, the medium in all groups was removed and substituted for glucose-free Earle's Balanced Salt solution (EBSS; Gibco; Thermo Fisher Scientific, Inc.) that was pre-incubated with $95 \% \mathrm{~N}_{2}$ and $5 \% \mathrm{CO}_{2}$ for $0.5 \mathrm{~h}$ to remove the oxygen in the medium. To induce an OGD condition, the cells were then incubated for $12 \mathrm{~h}$ in an airtight box filled with $95 \% \mathrm{~N}_{2}$ and $5 \% \mathrm{CO}_{2}$. Meanwhile, the cells in the control group were treated with EBSS supplemented with $10 \mathrm{mmol} / \mathrm{l}$ glucose in $\mathrm{CO}_{2}$ incubator.

Cell viability assay. The cell viability of astrocytes was determined by an MTT assay. Non-treated cells were regarded as the control group. Briefly, $0.5 \mathrm{mg} / \mathrm{ml}$ MTT reagent (Sigma-Aldrich; Merck Millipore) was added to each well (1x10 4 cells/well) following $12 \mathrm{~h}$ of exposure to OGD and incubated for $4 \mathrm{~h}$ at $37^{\circ} \mathrm{C}$. Dimethylsulfoxide $(10 \% ; 100 \mu \mathrm{l})$ was then added to dissolve the blue reaction product formazan by shaking the plates at room temperature for $10 \mathrm{~min}$. The absorbance value at $570 \mathrm{~nm}$ was monitored by using a microplate reader (SpectraMax M5; Molecular Devices, LLC, Sunnyvale, CA, USA). Each experiment was carried out in triplicate.
Lactate dehydrogenase $(\mathrm{LDH})$ release assay. $\mathrm{LDH}$ release was assessed in order to evaluate the extent of cell injury using a LDH cytotoxicity detection kit (Roche Applied Science, Penzberg, Germany) according to the manufacturer's instructions. Following exposure to OGD for $12 \mathrm{~h}$, the culture supernatant was harvested and dead cells were removed by centrifugation. The remaining supernatant was used to determine LDH levels. Absorbance at $492 \mathrm{~nm}$ was read using a microplate reader. Each experimental was done in triplicate.

Terminal deoxynucleotidyl transferase dUTP nick end labeling (TUNEL) staining. A TUNEL assay was performed to detect the staining of astrocytes cells using a commercially available kit (Promega Corporation, Madison, WI, USA) according to the manufacturer's instructions. A total of $12 \mathrm{~h}$ after exposure to OGD, the astrocytes were collected, washed with PBS, and examined under a fluorescence microscope.

Apoptosis assay. Cell apoptosis was detected by Annexin $\mathrm{V}-\mathrm{Cy} 5$ and propidium iodide (PI) staining (BioVision, Inc., Milpitas, CA, USA) followed by fluorescence-activated cell sorting (FACS) analysis. The cells $\left(2 \times 10^{5} / 35 \mathrm{~mm}\right.$ culture dish) were collected, pelleted and re-suspended in Annexin V-binding buffer containing Annexin V-Cy5 and PI, and incubated at room temperature for $5 \mathrm{~min}$. Thereafter, the cells were evaluated with a FACS Calibur flow cytometer (BD Biosciences, Franklin Lakes, NJ, USA). The percentage of total apoptotic cells was (early apoptotic + apoptotic) calculated.

Enzyme-linked immunosorbent assay (ELISA). The levels of secreted tumor necrosis factor (TNF)- $\alpha$, interleukin (IL)-6, and IL-1 $\beta$ in the culture supernatants that were exposed to OGD for $12 \mathrm{~h}$ were evaluated by using a commercially available ELISA kit (EMD Millipore, Billerica, MA, USA) according to the manufacturer's instructions. Absorbance at $450 \mathrm{~nm}$ was read using a microplate reader.

Measurement of antioxidant levels. Total antioxidant capacity (TAC) levels were assessed using Randox total antioxidant status kit (Randox Laboratories, Ltd., Crumlin, Northern Ireland). Briefly, the cultured astrocytes were collected following $12 \mathrm{~h}$ of exposure to OGD, washed twice with PBS, and lysed with $10 \mathrm{mM}$ phosphate buffer. Following centrifugation at $300 \mathrm{x} \mathrm{g}$ for $10 \mathrm{~min}$ at $4^{\circ} \mathrm{C}$, the supernatant was collected to evaluate the levels of TAC.

Western blot analysis. Following $12 \mathrm{~h}$ of exposure to OGD, astrocyte cultures were collected and washed with ice-cold PBS. The proteins were extracted from the cells using RIPA lysis buffer (Cell Signaling Technology, Inc., Danvers, MA, USA). The protein concentrations were determined using a BCA protein assay kit (Pierce; Thermo Fisher Scientific, Inc.) according to the manufacturer's instructions. Equal amounts of the protein samples $(20 \mu \mathrm{g})$ were resolved on $10-12 \%$ SDS-PAGE, and transferred onto a polyvinylidene difluoride membrane (Bio-Rad Laboratories, Hercules, CA, USA). The membranes were then blocked with $5 \%$ nonfat dry milk in TBS with $0.1 \%$ Tween (TBST) for $1 \mathrm{~h}$ at room temperature. The membranes were incubated overnight at $4^{\circ} \mathrm{C}$ with rabbit anti-polyclonal intercellular adhesion molecule (ICAM)-1 

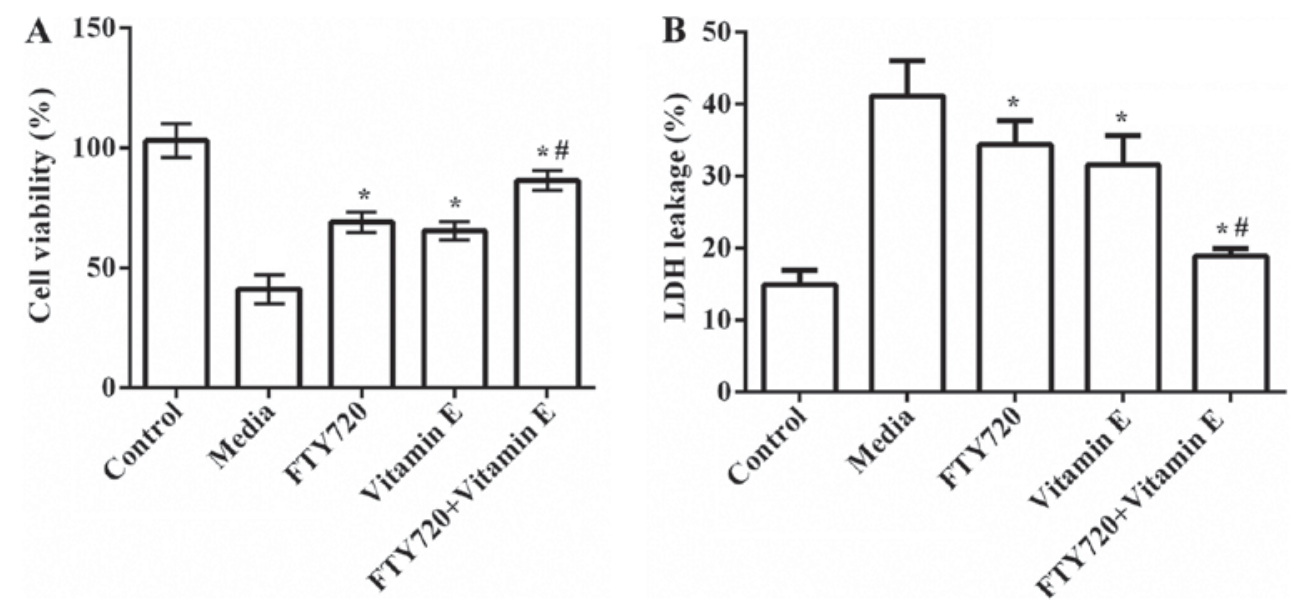

Figure 1. Combined effects of FTY720 and vitamin E on cell viability and LDH release. (A) The cell viability is markedly increased by pre-treatment with FTY720 or vitamin E. The cell viability is markedly higher in the FTY720 combined with vitamin E group than that in the FTY720 group or vitamin E group. (B) Pre-treatment with FTY720 or vitamin E markedly attenuates LDH leakage when compared to the media group, and while pre-treatment with FTY720 combined with vitamin E represents a more protective effect. ${ }^{*} \mathrm{P}<0.05$ vs. media group. ${ }^{~} \mathrm{P}<0.05$ vs. FTY720 or vitamin E group LDH, lactate dehydrogenase.

(catalog no. ab124760; 1:1,000), vascular cell adhesion molecule (VCAM)-1 (catalog no. ab215380; 1:1,000), chemokine (C-X-C motif) ligand (CXCL)-10 (catalog no. ab7206; 1:1,000), heme oxygenase (HO)-1 (catalog no. ab68477; 1:1,000) or superoxide dismutase (SOD)-1 (catalog no. ab16831; 1:1,000) antibody. All antibodies were obtained from Abcam (Cambridge, MA, USA). The membranes were then incubated with horseradish peroxidase-conjugated secondary antibody (catalog no. ab191866; 1:5,000; Abcam) for $2 \mathrm{~h}$ at room temperature. The positive bands were visualized with enhanced chemiluminescence western blotting substrate (Pierce; Thermo Fisher Scientific, Inc.) and autoradiography film. $\beta$-actin was used as an internal control.

Statistical analysis. All data were expressed as the mean \pm standard deviation. The statistical significance of differences among different groups was evaluated using SPSS software (version, 18.0; SPSS Inc., Chicago, IL, USA) with one-way analysis of variance. The Tukey-Kramer's post hoc test was performed for the multiple comparisons. $\mathrm{P}<0.05$ was used to indicate a statistically significant difference.

\section{Results}

Combined effects of FTY720 and vitamin E on cell viability on LDH release. To explore the combined effect of FTY720 and vitamin $\mathrm{E}$ on cerebral ischemia, the cultured rat astrocytes were subjected to medium, FTY720, vitamin E, or FTY720 combined with vitamin E. A total of $24 \mathrm{~h}$ later, the cultured astrocytes were exposed to OGD for $12 \mathrm{~h}$ to simulate cerebral ischemia. The combined effect of FTY720 and vitamin E on cell viability and LDH release was initially investigated. As indicated in Fig. 1A, the results demonstrated that the cell viability was significantly decreased by exposure to OGD when compared to the control group $(\mathrm{P}=0.032)$. However, the cell viability was markedly increased by pre-treatment with FTY720 or vitamin $\mathrm{E}$ compared to non-treatment $(\mathrm{P}=0.023$ or $\mathrm{P}=0.036$ ). No significant differences were observed between the FTY720 group and vitamin E group. In addition, the cell viability was markedly higher in the FTY720 combined with vitamin E group than that in the FTY720 group or vitamin E group $(\mathrm{P}=0.029$ or $\mathrm{P}=0.018)$.

Following this, the combined effect of FTY720 and vitamin $\mathrm{E}$ on $\mathrm{LDH}$ release was investigated, which is another indicator of cell toxicity (16). As presented in Fig. 1B, LDH leakage was significantly increased when the cells were exposed to $12 \mathrm{~h}$ OGD compared to the control group $(\mathrm{P}=0.034)$. Pre-treatment with FTY720 $(\mathrm{P}=0.031)$ or vitamin $\mathrm{E}(\mathrm{P}=0.019)$ significantly attenuated OGD-induced LDH leakage, and while pre-treatment with FTY720 combined with vitamin $\mathrm{E}$ represented the best protective effect $(\mathrm{P}=0.013)$. These results indicated that pre-treatment with FTY720 combined with vitamin $\mathrm{E}$ presented a synergistic protective effect on OGD-induced cell viability and toxicity of astrocytes.

Combined effects of FTY72O and vitamin E on astrocyte death. A total of $12 \mathrm{~h}$ following exposure to OGD, apoptotic cell death was detected by TUNEL staining and an apoptosis assay. As demonstrated in Fig. 2A and B, there was a significantly higher number of TUNEL-positive cells in media exposed to OGD when compared with the control group $(\mathrm{P}=0.016)$. Pre-treatment with FTY720 or vitamin E significantly reduced the number of TUNEL-positive cells $(\mathrm{P}=0.024$ or $\mathrm{P}=0.017$ ), and pre-treatment with FTY720 combined with vitamin $\mathrm{E}$ presented the fewest number of TUNEL-positive cells $(\mathrm{P}=0.012)$. The results suggested that pre-treatment with FTY720 and vitamin E showed a synergistic protective effect on OGD-induced astrocyte death.

Combined effects of FTY720 and vitamin E on IL-1 $\beta, T N F-\alpha$, IL- 6 and antioxidant release. Exposure of astrocytes to OGD for $12 \mathrm{~h}$ lead to increased IL-1 $\beta$ ( $\mathrm{P}=0.034)$, TNF- $\alpha(\mathrm{P}=0.029)$ and IL-6 release $(\mathrm{P}=0.042)$, but significantly decreased TAC $(\mathrm{P}=0.038)$. Pre-treatment with FTY720 markedly reduced the release of IL-1 $\beta(\mathrm{P}=0.042)$, TNF- $\alpha(\mathrm{P}=0.038)$ and IL-6 $(\mathrm{P}=0.036)$, however had no effect on the release of antioxidant level, confirming that FTY720 protects against cerebral ischemia by reduction of the levels of pro-inflammatory cytokines. However, pre-treatment with vitamin E markedly increased the 
A

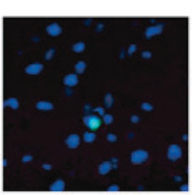<smiles>CC1CC1</smiles>

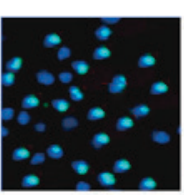

$4 a^{3}$

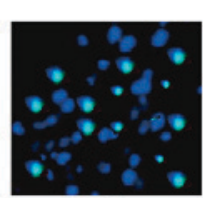

$\hat{r}^{n^{2}}$
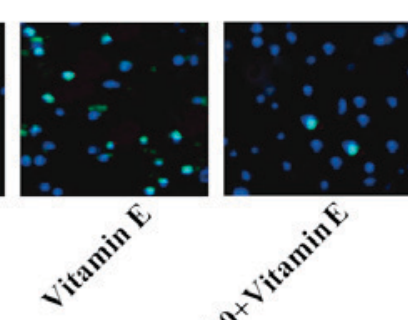

B

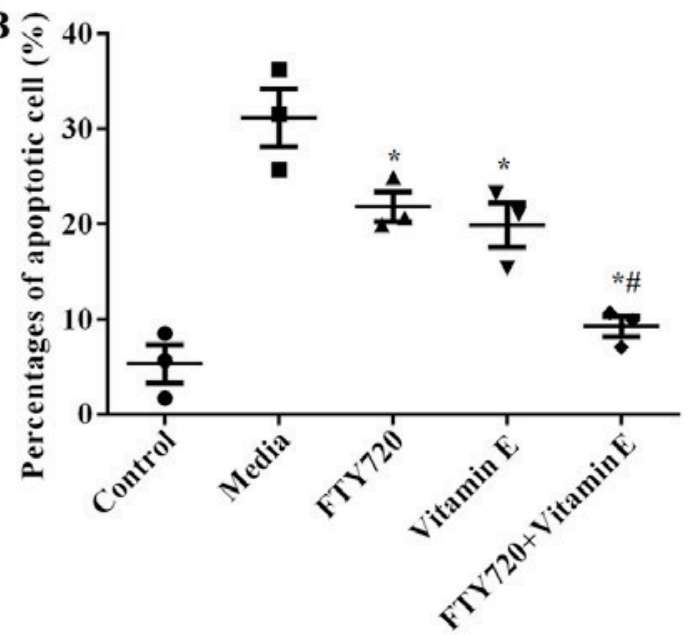

Figure 2. (A) Combined effects of FTY720 and vitamin E on astrocyte death. (B) Pre-treatment with FTY720 or vitamin E significantly reduces the number of TUNEL-positive cells compared with the media group, and pre-treatment with FTY720 combined with vitamin E has the fewest number of TUNEL-positive cells. " $\mathrm{P}<0.05$ vs. media group; ${ }^{\mathrm{P}}<0.05$ vs. FTY720 or vitamin E group. TUNEL, terminal deoxynucleotidyl transferase dUTP nick end labeling.
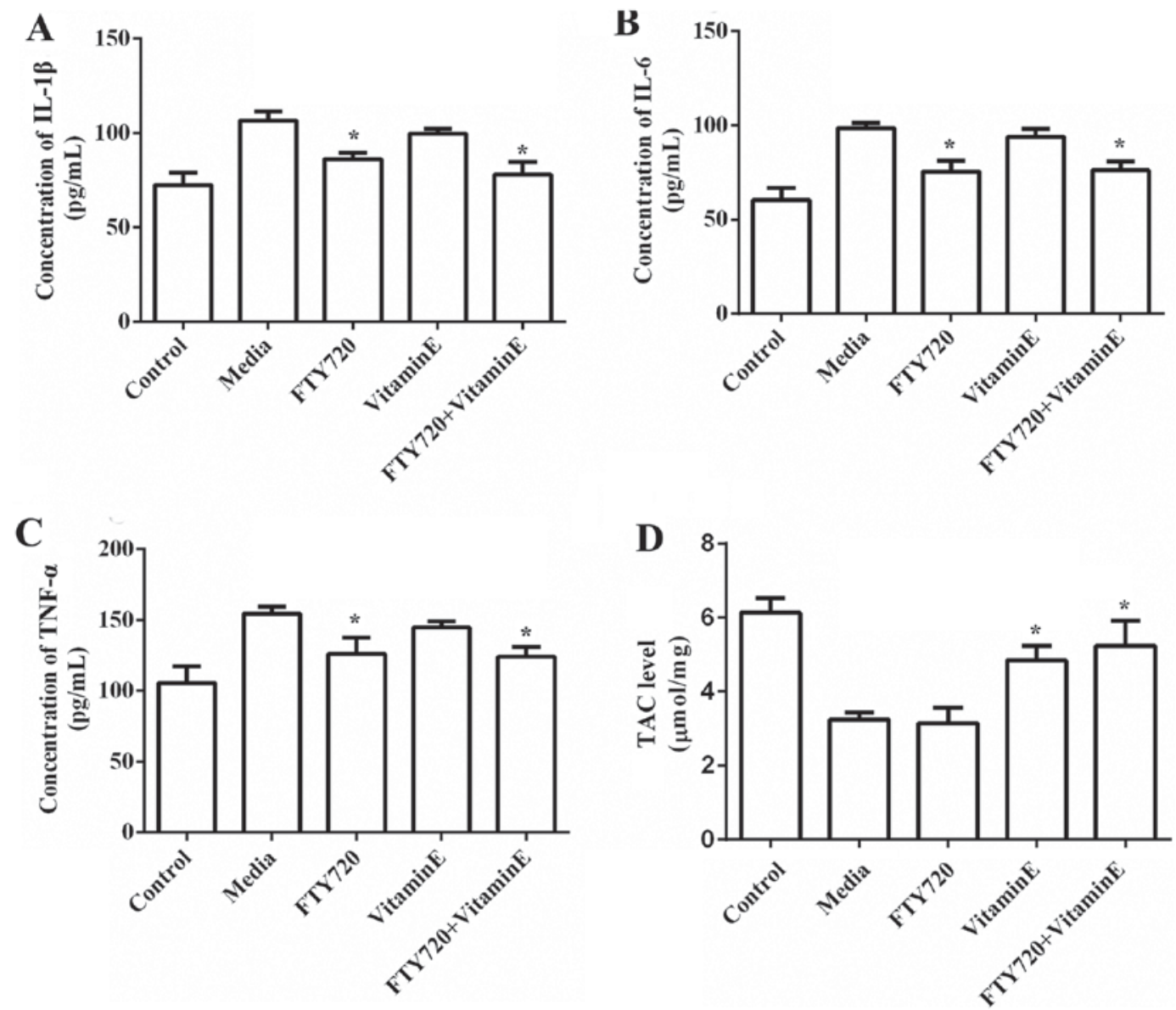

Figure 3. Combined effects of FTY720 and vitamin E on (A) IL-1 $\beta$, (B) IL-6, (C) TNF- $\alpha$, and (D) TAC. Pre-treatment with FTY720 markedly reduces the release of IL-1 $\beta$, TNF- $\alpha$, and IL-6, and while pre-treatment with vitamin E increases the release of antioxidants. Combination of FTY720 and vitamin E shows a synergistic effect. " $\mathrm{P}<0.05$ vs. media group. IL, interleukin; TNF, tumor necrosis factor; TAC, total antioxidant capacity.

release of antioxidant level $(\mathrm{P}=0.022)$ but had no effect on the release of IL-1 $\beta$, TNF- $\alpha$ and IL-6, confirming that vitamin $\mathrm{E}$ protects against cerebral ischemia by decrease of the levels of antioxidants. The combination of FTY720 and vitamin E significantly reduced the levels of IL- $1 \beta$, TNF- $\alpha$ and IL- 6 , however simultaneously elevated the levels of antioxidant, presenting a synergistic protective effect (Fig. 3A-D).

Combined effects of FTY720 and vitamin E on ICAM-1, VCAM-1, CXCL-10, HO-1 and SOD-1. Results of western 


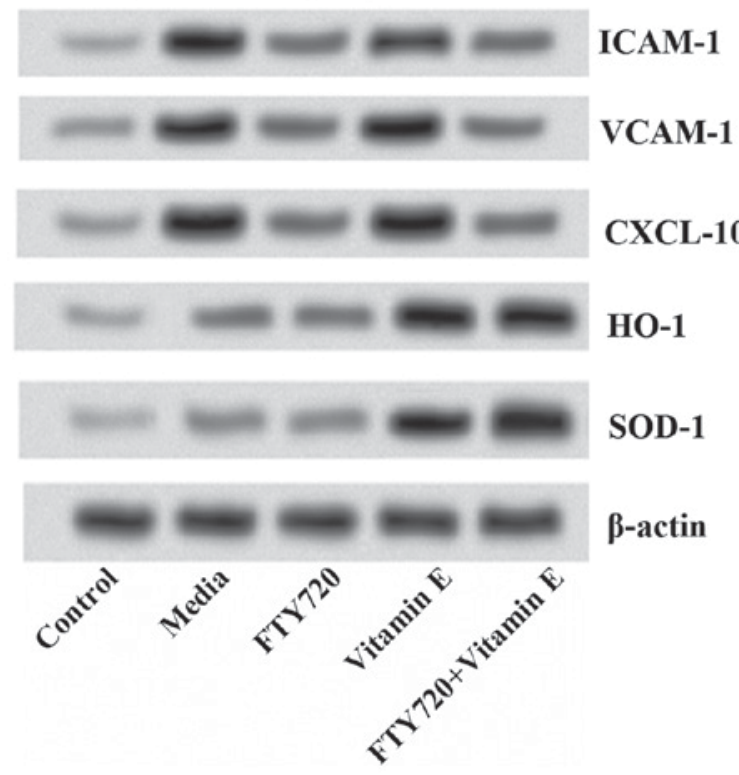

Figure 4. Combined effects of FTY720 and vitamin E on ICAM-1, VCAM-1, CXCL-10, HO-1 and SOD-1. Pre-treatment with FTY720 significantly reduces the protein levels of ICAM-1, VCAM-1 and CXCL-10, while pre-treatment with vitamin E markedly increases the levels of HO-1 and SOD-1. Additionally, pre-treatment with FTY720 combined with vitamin E indicates a synergistic effect. ICAM, intercellular adhesion molecule; VCAM, vascular cell adhesion molecule; CXCL, chemokine (C-X-C motif) ligand; HO, heme oxygenase; SOD, superoxide dismutase.

blot analysis indicated that exposure of astrocytes to OGD for $12 \mathrm{~h}$ markedly increased the levels of ICAM-1, VCAM-1 and CXCL-10, but markedly decreased the levels of HO-1 and SOD-1. Pre-treatment with FTY720 markedly reduced the protein levels of ICAM-1, VCAM-1 and CXCL-10, however appeared to have no effect on the levels of HO-1 and SOD-1. Meanwhile, pre-treatment with vitamin E markedly increased the levels of HO-1 and SOD-1, however, had no effect on the levels of ICAM-1, VCAM-1 and CXCL-10. Additionally, pre-treatment with FTY720 combined with vitamin E statistically reduced all the levels of ICAM-1, VCAM-1, CXCL-10, and simultaneously increased the levels of HO-1 and SOD-1, revealing a synergistic protective effect of FTY720 and vitamin E on cerebral ischemia (Fig. 4).

\section{Discussion}

Not only do astrocytes serve significant roles in regular neuronal function, but they are also involved in the pathology of stroke $(17,18)$. Following ischemic stroke, astrocytes may exhibit the ability of proliferation and differentiation (astrogliosis). Therefore, astrocytes were used in the present study and treated with or without FTY720, vitamin E, or combination of FTY720 and vitamin E. The results indicated that combination of FTY720 and vitamin E exerted a synergistic protective effect on astrocyte viability, toxicity and apoptosis induced by OGD. In addition, it was identified that FTY720 markedly reduced the levels of pro-inflammatory cytokines TNF- $\alpha$, IL-1 $\beta$ and IL-6, cell adherence molecules ICAM-1 and VCAM-1, and chemokine CXCL-10, whereas vitamin E increased the levels of antioxidant enzymes, HO-1 and SOD-1. The current results suggested that FTY720 combined with vitamin E possesses a synergistic neuroprotective effects in the simulated cerebral ischemia in vitro.

FTY720 is a novel immunomodulatory drug approved by the Food and Drug Administration to treat multiple sclerosis (19). FTY720 has been previously identified to reduce the trafficking of $\mathrm{T}$ cells, $\mathrm{B}$ cells, natural killer cells, and other S1PR-bearing cells into the CNS, leading to the reduction of relapses and brain volume loss $(12,14)$. FTY720 has emerged as a promising therapeutic modality, which has demonstrated the beneficial effects on experimental models of stroke $(13,20-23)$. The protective effect of FTY720 on stroke is predominantly involved in induction of lymphocytopenia, and concomitant reduction of microvascular thrombosis (23). The interactions between lymphocytes and endothelial cells enhance the dysfunction of microvascular, possibly leading to secondary infarct growth. In addition to FTY720, vitamin E has long been identified as a major lipid-soluble antioxidant protecting against cerebral ischemia. Kraft et al (23) suggested that vitamin E prevents cerebral ischemia neuronal apoptosis by lowering radical damage to hippocampal neurons. However, rare studies are focused on the combination effects of FTY720 and vitamin $\mathrm{E}$ on cerebral ischemia. Therefore, combination effects were studied in our present study. As indicated in our results, we observed that pre-treatment with either FTY720 or vitamin E both significantly elevated the astrocytes viability, and markedly decreased astrocytes cytotoxicity (LDH release) and number of apoptotic cells, demonstrating the protective roles of FTY720 or vitamin E in cerebral ischemia. Our results were in line with previous studies which showed FTY720 or vitamin $\mathrm{E}$ prevented against cerebral ischemia. These effects, however, were obviously enhanced by combination of FTY720 and vitamin E, indicating a synergistic protective effect. The underlying mechanisms were then investigated.

It has been well established that local and systemic inflammatory responses involving neutrophils, lymphocytes, macrophages and capillary endothelial cells are responsible for the development of ischemic stroke (24-26). Inflammatory molecules, such as adhesion molecules, chemokines and cytokines are involved in the inflammatory process. ICAM-1 and VCAM-1 are members of adhesion molecules, which are expressed on endothelial cells during inflammation $(27,28)$. Furthermore, the inflammatory process is promoted by various pro-inflammatory cytokines, such as TNF- $\alpha$, IL-6 and IL-1 $\beta$, produced by several subtypes of T cells (29). Chemokines, including CXCL-10, are secreted by the activated cells in ischemic regions to attract the inflammatory leukocytes into the region of infarction (30). Elevation of these inflammatory molecules clearly demonstrates detrimental effects on viable brain tissue (31). Therefore, administration of specific antagonists that reduce the release of inflammatory molecules is beneficial for preventing the development and deterioration of cerebral ischemia. In the current study, pre-treatment with FTY720 statistically decreased the levels of pro-inflammatory cytokines (TNF- $\alpha$, IL-1 $\beta$ and IL-6), adhesion molecules (ICAM-1 and VCAM-1) and chemokines (CXCL-10). However, these effects were not observed by pre-treatment with vitamin E, suggesting that reduction of the expression of inflammatory mediators caused by FTY720, but not by vitamin E, prevents against cerebral ischemia. 
On the other hand, one of the pathological mechanisms of cerebral ischemia is oxidative/nitrative stress (32). Oxidative/nitrosative stress results in cellular macromolecular destruction and cell death (33). HO is a microsomal enzyme that degrades heme from heme-containing proteins, leading to the production of carbon monoxide, iron and biliverdin (34). The characteristics of $\mathrm{HO}$ make it as an crucial antioxidant enzyme in the nervous system (35). HO-1 is a rate-limiting enzyme in heme catabolism, which has potent antioxidant and anti-apoptosis effects (36). Recently, some studies have suggested that overproduction of $\mathrm{HO}-1$ is neuroprotective against cerebral ischemia injury $(37,38)$. In addition, SOD-1 is a well-known antioxidant enzyme, responsible for detoxifying intracellular reactive oxygen species (ROS), thereby protecting cells from oxidative damage. It has been reported that overexpression of SOD-1 in transgenic rats or mice protects neurons from death after focal cerebral ischemia (39). Zhang et al (15) found that vitamin E protects against cerebral ischemia by inducing the expression of subunit of HIF-1 and its target genes, including HO-1. Administration of vitamin E slowed the onset and the progression of amyotrophic lateral sclerosis in SOD-1 transgenic mice (40). Similarly, in the present study, astrocytes pretreated with vitamin $\mathrm{E}$ presented higher levels of HO-1 and SOD-1; however, these effects were not observed by pre-treatment with FTY720, indicating an antioxidant effect of vitamin E but not FTY720.

In conclusion, the current study suggested that pre-treatment with FTY720 combined with vitamin E reveals a synergistic effect on cerebral ischemia. This provides novel therapeutic strategies for cerebral ischemia. However, animal experiments should be performed to confirm the results.

\section{References}

1. Tang Q, Han R, Xiao H, Shen J, Luo Q and Li J: Neuroprotective effects of tanshinone IIA and/or tetramethylpyrazine in cerebral ischemic injury in vivo and in vitro. Brain Res 1488: 81-91, 2012.

2. Suethanapornkul S, Kuptniratsaikul PS, Kuptniratsaikul V, Uthensut P, Dajpratha P and Wongwisethkarn J: Post stroke shoulder subluxation and shoulder pain: A cohort multicenter study. J Med Assoc Thai 91: 1885-1892, 2008.

3. WRITING GROUP MEMBERS, Lloyd-Jones D, Adams RJ, Brown TM, Carnethon M, Dai S, De Simone G, Ferguson TB, Ford E, Furie K, et al: Heart disease and stroke statistics-2010 update: A report from the American Heart Association. Circulation 121: e46-e215, 2010.

4. Urban PP, Wolf T, Uebele M, Marx JJ, Vogt T, Stoeter P, Bauermann T, Weibrich C, Vucurevic GD, Schneider A and Wissel J: Occurence and clinical predictors of spasticity after ischemic stroke. Stroke 41: 2016-2020, 2010.

5. Raichle ME: The pathophysiology of brain ischemia. Ann Neurol 13: 2-10, 1983.

6. Lees KR, Bluhmki E, von Kummer R, Brott TG, Toni D, Grotta JC, Albers GW, Kaste M, Marler JR, Hamilton SA, et al Time to treatment with intravenous alteplase and outcome in stroke: An updated pooled analysis of ECASS, ATLANTIS NINDS, and EPITHET trials. Lancet 375: 1695-1703, 2010.

7. Brinkmann V, Davis MD, Heise CE, Albert R, Cottens S, Hof R, Bruns C, Prieschl E, Baumruker T, Hiestand P, et al: The immune modulator FTY720 targets sphingosine 1-phosphate receptors. J Biol Chem 277: 21453-21457, 2002.

8. Yagi H, Kamba R, Chiba K, Soga H, Yaguchi K, Nakamura M and Itoh T: Immunosuppressant FTY720 inhibits thymocyte emigration. Eur J Immunol 30: 1435-1444, 2000.

9. Brinkmann V, Pinschewer DD, Feng L and Chen S: FTY720: Altered lymphocyte traffic results in allograft protection. Transplantation 72: 764-769, 2001
10. Jung CG, Kim HJ, Miron VE, Cook S, Kennedy TE, Foster CA, Antel JP and Soliven B: Functional consequences of S1P receptor modulation in rat oligodendroglial lineage cells. Glia 55: $1656-1667,2007$

11. Cannon RE, Peart JC, Hawkins BT, Campos CR and Miller DS: Targeting blood-brain barrier sphingolipid signaling reduces basal P-glycoprotein activity and improves drug delivery to the brain. Proc Natl Acad Sci USA 109: 15930-15935, 2012.

12. Cohen JA and Chun J: Mechanisms of fingolimod's efficacy and adverse effects in multiple sclerosis. Ann Neurol 69: 759-777, 2011.

13. Hasegawa Y, Suzuki H, Sozen T, Rolland W and Zhang JH: Activation of sphingosine 1-phosphate receptor-1 by FTY720 is neuroprotective after ischemic stroke in rats. Stroke 41: 368-374, 2010.

14. Wei Y, Yemisci M, Kim HH, Yung LM, Shin HK, Hwang SK, Guo S, Qin T, Alsharif N, Brinkmann V, et al: Fingolimod provides long-term protection in rodent models of cerebral ischemia. Ann Neurol 69: 119-129, 2011.

15. Zhang B, Tanaka J, Yang L, Yang L, Sakanaka M, Hata R, Maeda N and Mitsuda N: Protective effect of vitamin E against focal brain ischemia and neuronal death through induction of target genes of hypoxia-inducible factor-1. Neuroscience 126: 433-440, 2004

16. Broussas M, Broyer L and Goetsch L: Evaluation of antibody-dependent cell cytotoxicity using lactate dehydrogenase (LDH) measurement. Methods Mol Biol 988: 305-317, 2013.

17. Barreto G, White RE, Ouyang Y, Xu L and Giffard RG: Astrocytes: Targets for neuroprotection in stroke. Cent Nerv Syst Agents Med Chem 11: 164-173, 2011.

18. Sofroniew MV and Vinters HV: Astrocytes: Biology and pathology. Acta Neuropathol 119: 7-35, 2010.

19. Kappos L, Radue EW, O'Connor P, Polman C, Hohlfeld R, Calabresi P, Selmaj K, Agoropoulou C, Leyk M, Zhang-Auberson L, et al: A placebo-controlled trial of oral fingolimod in relapsing multiple sclerosis. N Engl J Med 362: 387-401, 2010

20. Shichita T, Sugiyama Y, Ooboshi H, Sugimori H, Nakagawa R, Takada I, Iwaki T, Okada Y, Iida M, Cua DJ, et al: Pivotal role of cerebral interleukin-17-producing gammadeltaT cells in the delayed phase of ischemic brain injury. Nat Med 15: 946-950, 2009.

21. Brunkhorst R, Kanaan N, Koch A, Ferreirós N, Mirceska A, Zeiner P, Mittelbronn M, Derouiche A, Steinmetz H, Foerch C, et al: FTY720 treatment in the convalescence period improves functional recovery and reduces reactive astrogliosis in photothrombotic stroke. PLoS One 8: e70124, 2013.

22. Czech B, Pfeilschifter W, Mazaheri-Omrani N, Strobel MA, Kahles T, Neumann-Haefelin T, Rami A, Huwiler A and Pfeilschifter J: The immunomodulatory sphingosine 1-phosphate analog FTY720 reduces lesion size and improves neurological outcome in a mouse model of cerebral ischemia. Biochem Biophys Res Commun 389: 251-256, 2009.

23. Kraft P, Göb E, Schuhmann MK, Göbel K, Deppermann C, Thielmann I, Herrmann AM, Lorenz K, Brede M, Stoll G, et al: FTY720 ameliorates acute ischemic stroke in mice by reducing thrombo-inflammation but not by direct neuroprotection. Stroke 44: 3202-3210, 2013

24. Jin R, Yang G and Li G: Inflammatory mechanisms in ischemic stroke: Role of inflammatory cells. J Leukoc Biol 87: 779-789, 2010.

25. Huang J, Upadhyay UM and Tamargo RJ: Inflammation in stroke and focal cerebral ischemia. Surg Neurol 66: 232-245, 2006.

26. De Simoni MG, Milia P, Barba M, De Luigi A, Parnetti L and Gallai V: The inflammatory response in cerebral ischemia: Focus on cytokines in stroke patients. Clin Exp Hypertens 24: $535-542,2002$.

27. Matsuo Y, Onodera H, Shiga Y, Shozuhara H, Ninomiya M, Kihara T, Tamatani T, Miyasaka M and Kogure K: Role of cell adhesion molecules in brain injury after transient middle cerebral artery occlusion in the rat. Brain Res 656: 344-352, 1994.

28. Connolly ES Jr, Winfree CJ, Springer TA, Naka Y, Liao H, Yan SD, Stern DM, Solomon RA, Gutierrez-Ramos JC and Pinsky DJ: Cerebral protection in homozygous null ICAM-1 mice after middle cerebral artery occlusion. Role of neutrophil adhesion in the pathogenesis of stroke. J Clin Invest 97: 209-216, 1996.

29. Saito K, Suyama K, Nishida K, Sei Y and Basile AS: Early increases in TNF-alpha, IL-6 and IL-1 beta levels following transient cerebral ischemia in gerbil brain. Neurosci Lett 206: 149-152, 1996. 
30. Wang X, Ellison JA, Siren AL, Lysko PG, Yue TL, Barone FC, Shatzman A and Feuerstein GZ: Prolonged expression of interferon-inducible protein-10 in ischemic cortex after permanent occlusion of the middle cerebral artery in rat. J Neurochem 71: 1194-1204, 1998.

31. Merrill JE and Benveniste EN: Cytokines in inflammatory brain lesions: Helpful and harmful. Trends Neurosci 19: 331-338, 1996.

32. Lyden P and Wahlgren NG: Mechanisms of action of neuroprotectants in stroke. J Stroke Cerebrovasc Dis 9: 9-14, 2000

33. Dalle-Donne I, Scaloni A, Giustarini D, Cavarra E, Tell G, Lungarella G, Colombo R, Rossi R and Milzani A: Proteins as biomarkers of oxidative/nitrosative stress in diseases: The contribution of redox proteomics. Mass Spectrom Rev 24: 55-99, 2005.

34. Elbirt KK and Bonkovsky HL: Heme oxygenase: Recent advances in understanding its regulation and role. Proc Assoc Am Physicians 111: 438-447, 1999.

35. Schipper HM: Heme oxygenase expression in human central nervous system disorders. Free Radic Biol Med 37: 1995-2011, 2004.

36. Wu ML, Ho YC, Lin CY and Yet SF: Heme oxygenase-1 in inflammation and cardiovascular disease. Am J Cardiovasc Dis 1: 150-158, 2011.
37. Chao XD, Ma YH, Luo P, Cao L, Lau WB, Zhao BC, Han F, Liu W, Ning WD, Su N, et al: Up-regulation of heme oxygenase-1 attenuates brain damage after cerebral ischemia via simultaneous inhibition of superoxide production and preservation of NO bioavailability. Exp Neurol 239: 163-169, 2013.

38. Panahian N, Yoshiura M and Maines MD: Overexpression of heme oxygenase-1 is neuroprotective in a model of permanent middle cerebral artery occlusion in transgenic mice. J Neurochem 72: 1187-1203, 1999.

39. Chan PH, Kawase M, Murakami K, Chen SF, Li Y, Calagui B, Reola L, Carlson E and Epstein CJ: Overexpression of SOD1 in transgenic rats protects vulnerable neurons against ischemic damage after global cerebral ischemia and reperfusion. J Neurosci 18: 8292-8299, 1998.

40. Gurney ME, Cutting FB, Zhai P, Doble A, Taylor CP, Andrus PK and Hall ED: Benefit of vitamin E, riluzole, and gabapentin in a transgenic model of familial amyotrophic lateral sclerosis. Ann Neurol 39: 147-157, 1996. 